\title{
建筑工程结算审计存在的问题及应对策略
}

\author{
王文喜 \\ 浙江同诚建设管理有限公司，浙江，嘉兴 314500
}

[摘要]近年来，在诸多利好因素的影响下，使得我国各个领域都得到了良好的发展，尤其是建筑工程行业发展十分迅猛。在 整个建筑工程行业中，建筑工程造价是施工单位控制工作的侧重点，在社会经济水平快速提升的影响下，使得人们对建筑工 程造价的准确性越发的重视, 建筑工程造价准确性往往都与工程施工工作效率存在一定的关联, 所以应当给予重点关注。因 为当下我国在综合了多方面情况的基础上, 针对建筑工程造价实施了切实的改革, 从而使得造价计算方法从原有的定额计价 方法过度成为了工程量清单计价方法, 这样就对造价审计工作提出了更高的要求, 并且也会对审计工作的开展形成一定的阻 碍。所以, 在实施工程造价审计工作的时候, 要想从根本上提升审计工作的质量, 最为重要的就是需要对牵涉到的所有问题 进行深入的分析研究, 并且对各项岗位职责进行细致的花费, 这样才能为审计工作的实时给予规范性指导, 推动建筑工程行 业的稳步健康发展。

[关键词]建筑工程; 结算审计; 问题策略

DOI：10.33142/ec.v3i7.2335 中图分类号：TU723.3;F239.63 文献标识码：A

\section{Problems and Countermeasures of Construction Project Settlement Audit}

\author{
WANG Wenxi
}

Zhejiang Tongcheng Construction Management Co., Ltd., Jiaxing, Zhejiang, 314500, China

\begin{abstract}
In recent years, under the influence of many favorable factors, all fields in China have been well developed, especially the construction engineering industry has developed rapidly. In the whole construction industry, construction cost is the focus of construction unit control work. Under the influence of rapid improvement of social and economic level, people pay more and more attention to the accuracy of construction cost. The accuracy of construction cost is often related to the efficiency of engineering construction work, so it should be focused. Because at present, on the basis of comprehensive situation in many aspects, China has implemented practical reform for construction engineering cost, which makes the cost calculation method from the original quota valuation method to the bill of quantities valuation method, which puts forward higher requirements for the cost audit work and also forms certain obstacles to the audit work. Therefore, in the implementation of project cost audit work, in order to fundamentally improve the quality of audit work, the most important thing is to carry out in-depth analysis and research on all the issues involved and to carry out detailed cost of various post responsibilities, so as to give normative guidance for the real-time audit work and promote the steady and healthy development of construction engineering industry.
\end{abstract}

Keywords: construction engineering; settlement audit; problem strategy

引言

在社会快速发展的影响下, 使得建筑工程行业发展取得了良好的成绩, 而工程造价是整个建筑工程行业中的主要 问题, 在一个建筑工程项目中, 工程结算审计工作的效果与建筑工程造价的准确性存在密切的关联, 并且这项工作并 非是短时间的一项工作, 而是需要渗透在各个工程工序中的一项重要工作。经过大量的实践调查我们发现, 当下建筑 工程结算审计中存在诸多的问题, 对于工程整体造价科学性造成了严重的不良影响, 所以我们需要充分结合各方面实 际情况来对结算审计中所存在的问题加以准确判断, 利用有效的方式方法来加以解决, 从而促进工程造价准确性的不 断提升。工程结算审计工作与工程建设方的经济利益存在密切的关联, 是合同法中的一项十分关键的内容, 所以我们 应当对结算审计工作加以侧重关注, 借助有效的方式方法来促进结算设计工作的整体水平的不断提升。

\section{1 建筑工程结算审计的基本内容}

\section{1 工程数量审核}

首先, 判断工程数量的计算范围, 诸如: 在实施建筑工程施工工作的过程中, 需要对各项施工工作进行合理的安 排。其次, 针对工程施工现场进行规划, 诸如: 在实施高层建筑工程施工工作的时候, 往往需要使用到脚手架, 而对 
脚手架需要花费的各项费用, 需要进行科学的计划。最后, 针对建筑工程各项分支结构实际大小与设计图纸进行对比, 针对签证凭证加以切实的审核, 侧重针对签证与设计变更是不是与施工结果相一致 ${ }^{[1]}$ 。

\section{2 工程套用单价审核}

首先, 需要针对直接套用定额单价加以严格的审核, 详细的来说就是针对项目建设与设计图二者之间的统一性加 以审核。其次, 在针对定额单价进行换算的时候, 在直接使用单价的时候, 针对允许换算的内容, 可以结合相关规定 实施审核工作。其次, 还需要读审核换算方法的切实性加以保证, 规避对施工单价的准确性造成负面影响。再有, 在 针对补充定额内容实施审核工作的时候, 对于施工过程中的人员安排, 机械设备安排等进行切实性的审核 ${ }^{[2]}$ 。

\section{3 综合费用审核}

在实际组织开展工程施工工作的过程中, 在对施工过程中涉及到的各项费用支出进行审核工作的时候, 务必要切 实的遵照相关行政机构制定的规范标准落实审核工作，确保各项工作的效率和效果。

\section{2 建筑工程结算审计过程中存在的问题分析}

\section{1 合同的签订存在漏洞}

签署合同的主要目的就是借助严禁的法律法规以及方式方法来保证双方的利益。建筑施工单位在进行结算审计工 作的时候, 往往会发生合同签署不规范的情况, 一些合同中也会发生与招标文件不统一的情况, 这样对于后期施工工 作的开展就会产生诸多的限制。部分企业没有针对合同内容与招标文件内容进行对比, 这样就会造成签署的合同与招 标文件内容不统一的情况发生, 建筑规模与中标价格也会存在差异, 最终会对工程建设单位的权益造成损害 ${ }^{[3]}$ 。

\section{2 忽视对建筑项目内部控制风险审计}

因为工程项目涉及到的工作量较为巨大, 所以具有非常明显的复杂性和综合性, 要想设立详细的内部控制制度, 对项目建设工作进行全面的监督, 针对项目中所存在的风险点进行合理的把控, 这样才能保证项目建设的效率和效果。 但是就现实情况来说, 工程建设单位、施工单位以及监理机构只是对事中控制和事后处理工作十分的重视, 而对于事 前准备工作较为忽视。如果相关工程管理工作人员只是重视工程进度和施工质量, 而不关注项目的投资控制工作, 那 么必然会造成造价结算超出预算的情况发生。建筑材料的采买工作存在贪污的情况, 诸如: 在进行施工材料采买工作 的时候制作假账，这样就会导致账目的混乱，从而会对后期工程审计工作的开展造成一定的限制。

\section{3 材料成本难以确定}

所有的企业因为在市场经济发展的影响下都取得了良好的进步, 就现如今市场情况来说, 存在大量的质量低劣的 建筑材料, 这样对于建筑材料市场价格会造成严重的冲击, 各个厂家材料价格的差异十分严重, 这样就会导致结算审 计工作人员不能依据标准来实施材料结算审计。再加上市场价格波动较为巨大, 实践中所使用的材料价格与市场价格 存在明显的差别, 从而会对施工成本的测定和评估工作造成一定的阻碍。在实施结算审计工作的时候, 尽管可以依据 原始凭证来进行对比, 但是往往还是会出现价格混乱的情况, 这样对于结算审计工作来说是非常不利的 ${ }^{[4]}$ 。

\section{3 建筑工程结算审计质量改进}

\section{1 做好审计准备, 确保资料完善}

建筑工程结算审计工作具有非常明显的复杂性, 并且晖涉到的内容较多, 在正式开展结算设计工作之前务必要做 好充分的准备工作。建筑工程计算审计涉及到的材料准备工作的效果往往会对后续审计工作的实施造成一定的影响, 所以要想确保审计工作的有序开展, 那么就需要做好充足的准备工作, 在实施工程结算设计工作之前需要运用有效的 方式方法来对各项信息资料进行收集, 这样才能为后续工程结算审计工作的有序开展创造良好的基础, 并且还可以保 证对施工单位各方面实际情况加以全面的了解。其次, 在将全部资料收集齐全之后, 需要结合工程各方面实际情况来 制定完善的工程审计方案, 充分参考工程设计前期的调查工作结果, 来制定切实可行的审计流程, 为各项审计工作的 开展给予规范性指导 ${ }^{[5]}$ 。

\section{2 严格遵守审计规则, 强化材料价格管理}

在针对建筑工程项目实施结算审计工作的过程中, 务必要安排专人对各项信息数据进行准确的记录。通常情况下, 建筑工程成本结算牵涉到的下面几方面的支出, 诸如: 工程人工成本、施工原材料成本、工程机械采买等等。在组织 落实工程项目结算审计工作的过程中, 工作人员务必要严格遵照规范要求来推进各项工作, 这样才能从根本上确保审 计工作的效率和效果, 并且要安排专业人员对工程建造完成之后的各项信息数据与前期设计各项信息数据进行比对, 
并且要严格遵照要求对工程施工质量进行全面的检查, 有效的促进工程施工质量的提升, 这样才能为后续各项工作的 实施创造良好的基础。

\section{3 确保审计意见表达清晰, 强化内部审计工作}

在建筑工程结算审计工作结束之后, 需要安排工作人员针对结算设计工作针对审计工作的经过进行详细的记录, 并且制定完整的审计报告。在设计报告中务必要严格按照规范要求进行各项内容的编制, 并且要对工程施工工作进行 全面的评价, 最终将编制的书面审计报告上报相关管理机构。在建筑工程结算审计报告中, 要对工程结算审计结果进 行详细的说明, 并且要保证内容简明扼要, 真正的做到有理有据 ${ }^{[6]}$ 。

\section{4 加强管理, 完善合同内容}

就一个完整的建筑工程项目来说, 针对工程造价实施切实的审计工作其意义是十分关键的, 在建筑工程双方签署 施工合同之后, 因为合同内容中可能会存在一定的不规范的情况, 针对这个问题就需要审计工作人员进行严格的审查, 一旦发现问题可以进行纠正，这样就可以有效的避免合同风险情况的发生。

\section{4 建筑工程结算审计技巧}

\section{1 重点审核法}

在将重点审计方法切实的引用到建筑工程审计工作之中的时候, 可以有效的将审计工作的重点凸显出来, 部分建 筑工程涉及到的工作量较为巨大, 并且整体成本较多, 施工工作具有明显的复杂性, 所以可以选择运用重点审核法, 有效的提升审计工作的整体效率。

\section{2 分组审核法}

分组审核法最为突出的优越性就是实际操作相对简单便捷, 在实际运用这一方法来实施工程项目结算审计工作的 额时候, 需要针对某个审核项目进行具体的划分, 之后将存在关联性较大的审核内容当作是审核工作的标准, 最后针 对各项内容进行逐一的审核。其次, 很多审核对象之间存在一些联系, 所以会影响到审核结果的准确性, 而运用分组 审核的方法可以有效的避免这个问题发生。

\section{3 对比审核法}

在将对比审核方法进行实践运用的过程中，务必要对涉及到的所有信息资料进行综合分析，对各个工序进行综合 掌握, 随后进行适当的整合, 为结算审计工作提供参考。

\section{5 结束语}

综合以上阐述我们总结出, 建筑工程结算审计工作的效果与企业未来发展存在一定的影响, 并且具有明显的政策 性、规范性特征。所以, 建筑工程结算设计在工程造价管理工作中的作用是十分巨大的, 所以在实际开展建筑工程结 算设计工作的时候, 要想从根本上对审计工作的效率和效果加以保证, 那么最为重要的就是需要审计工作人员充分结 合相关法律条款来推进各项审计工作的落实, 保证审计结果的高效性和准确性, 这样才能更好的对结算造价加以切实 的管控。

\section{[参考文献]}

[1]师晓峰.建筑工程结算审计存在的问题及应对策略 [J].四川水泥, 2020 (01) : 226 .

[2]张敏敏.建筑工程结算审计存在的问题及应对策略 [J]. 现代物业 (中旬刊), 2020 (01): 117 .

[3] 葛玉萍. 建筑工程结算审计存在的问题及应对策略 [J]. 建材与装饰, 2019(31): 184-185.

[4]宋承亮. 建筑工程结算审计存在的问题及应对策略 [J]. 城市建设理论研究 (电子版), 2019 (29): 15 .

[5]宋华.建筑工程预结算审计存在问题及应对策略 [J]. 当代会计,2019(09) : 83-84.

[6]于兵.工程结算审计中存在的问题及应对措施 [J]. 石油化工技术与经济, 2015,31 (06) : 9-13.

作者简介: 王文喜 (1987.4-), 男, 安徽建筑工业学院城市建设学院, 土木工程专业, 浙江同诚建设管理有限公司, 全过程咨询项目负责人，中级工程师。 